\title{
O Uso Associado de Recursos Manipulativos Digitais e Não-Digitais para o Ensino- Aprendizagem de Matemática
}

\author{
Aline Fraga Rosa \\ alinnefraga@yahoo.com.br \\ Programa de Pós Graduação em Ensino de Matemática \\ Universidade Federal do Rio Grande do Sul (UFRGS) \\ Porto Alegre - RS - Brasil
}

\section{Resumo}

No presente artigo apresentamos as possíveis contribuições que o uso integrado de recursos manipulativos digitais e não-digitais podem trazer na aprendizagem de matemática, mais especificamente na compreensão de alguns conceitos sobre polígonos regulares. Apoiado nas teorias piagetianas de construção do conhecimento e nos resultados obtidos, podemos afirmar que o aprendizado ocorre naturalmente quando explorado em diferentes âmbitos educativos. As atividades foram realizadas com alunos de $6^{a}$ série, numa escola da rede privada de Porto Alegre.

Palavras-chave: recursos manipulativos digitais e não-digitais, aprendizagem, matemática.

\section{The Associated Use of Digital and Non-Digital Manipulative Resources for the Teaching-Learning of Mathematics}

\begin{abstract}
In this article we present the possible contributions that the use of digital and non-digital manipulative resources can bring in the learning of mathematics, more specifically in the understanding of some concepts about regular polygons. Supported by Piaget's theory of knowledge construction and in the obtained results, we can affirm that learning occurs naturally when explored in different educational range. The activities were performed with $6^{\text {th }}$ grade students, in a private school of Porto Alegre.
\end{abstract}

Keywords: digital and non-digital manipulative resources, learning, mathematics.

\section{Introdução e embasamento teórico}

Segundo Fiorentini (1995) o grande desafio da educação é promover a aprendizagem de conhecimentos, e desenvolver habilidades e competências de forma significativa e duradoura para todas as crianças. Muito se tem pensado e discutido a respeito de estratégias e recursos que tornem a aprendizagem de matemática mais produtiva e interessante para os alunos.

Grande parte dos estudantes apresenta um sentimento de fracasso em relação à matemática, tendo em vista que esta é considerada, muitas vezes, como uma disciplina baseada em técnicas repetitivas que faz uso de uma simbologia desprovida de significação.

Segundo Fagundes (1977), entende-se por aprendizado de matemática a capacidade de relacionar esta área do conhecimento com a realidade, bem como de 
entender o significado de suas simbolizações. Entendemos que os processos de aprendizagem devem criar condições favoráveis para a construção de conceitos de matemática, por isso, os professores devem trabalhar os conteúdos via metodologia atraente e diversificada, com a finalidade de auxiliar e possibilitar que os estudantes entendam e compreendam o que estão aprendendo.

É preciso que a matemática seja vista como uma área do conhecimento desafiante, interessante e estimuladora da curiosidade. Isso tem por objetivo fazer que seu ensino e seu aprendizado sejam prazerosos e possibilite ao aluno (re)construir concepções e conceitos, além disso, as aulas devem permitir o desenvolvimento da criatividade e do pensamento autônomo.

Conforme Piaget, para que o sujeito tenha condições de organizar, estruturar e explicar o mundo a sua volta e a si mesmo, é necessário conhecer o processo de construção de significados que leva ao conhecimento. Conhecer é vivenciar e interagir, não apenas explicar. É necessário que sejam estabelecidas relações (FIORENTINI, 1995 p.20).

A aprendizagem da matemática resulta de atos mentais que reorganizam a experiência vivenciada pelo aluno. A matemática não pode ser considerada um conhecimento pronto, acabado e descontextualizado historicamente. Assim, os recursos manipulativos digitais e não-digitais surgem como um apoio didático e como uma estratégia de ensino, capaz de proporcionar uma aprendizagem que desenvolva competências e habilidades, como, por exemplo, a capacidade de abstrair conceitos e relacioná-los com a realidade, de visualizar geometricamente algumas situações, etc., tornando as aulas mais atrativas e dinâmicas.

A discussão sobre o uso desses materiais não é recente, mas ressaltamos a importância de se trabalhar conjuntamente com materiais concretos e com objetos digitais de aprendizagem, pois a utilização de um complementa a utilização do outro.

Quando o aluno é convidado a interagir com diversos conceitos matemáticos, a partir da utilização de variados recursos didático-pedagógicos estamos aumentando a probabilidade e possibilitando que ele aprenda esses conceitos, e não simplesmente decore para repetir posteriormente.

Os recursos manipulativos digitais e não-digitais quando usados como complementação um do outro, permitem a exploração de propriedades que são observáveis ora nos desenhos e nos materiais concretos, ora nos objetos digitais e softwares de geometria dinâmica.

Essa oportunidade de manipular livremente e experimentar, que os recursos manipulativos oferecem, levam o estudante a reconhecer as propriedades dos objetos que estão manuseando. Esse tipo de atividade envolve os alunos, abrange diversas estruturas cognitivas e desenvolve uma certa autonomia em cada um.

O conhecimento, segundo Piaget, não é uma cópia da realidade. Não resulta de olhar e fazer simplesmente uma copia mental, uma imagem de um objeto. Para conhecer um objeto, um fato, é preciso agir sobre ele, modificá-lo, transformá-lo, compreender o processo dessa transformação e, como consequência entender a maneira como o objeto é construído. (FAGUNDES, 1977, p. 3).

Segundo Piaget (apud Fagundes, 1977), a importância dessas ações e experimentações lógico-matemáticas constitui-se como uma preparação para o desenvolvimento do pensamento dedutivo, ou seja, das abstrações que serão necessárias mais adiante. 
Há diferenças entre as experiências físicas e as experiências lógico-matemáticas. Nas experiências físicas, a criança age sobre o objeto e consegue algum conhecimento por abstração. Por exemplo, ela identificará que um prato é mais pesado que uma colher segurando um em cada mão e manuseando os dois. Já nas experiências lógicomatemáticas, o conhecimento é adquirido das ações que o sujeito realiza sobre o objeto, como ordenar, enumerar e estabelecer correspondências.

\begin{abstract}
Assim, o trabalho com recursos digitais e não-digitais fornece suporte tanto para as experiências físicas que são base para as operações lógicomatemáticas que, ulteriormente, podem dispensar a ação manipulativa, quanto para as experiências lógico-matemáticas que, da mesma forma, têm papel imprescindível na generalização das ações e das coordenações das ações do sujeito. (HOFFMANN et al, 2009, p. 4).
\end{abstract}

Gabba (1975) citado por Fagundes (1977) propõe um esquema para a utilização dos materiais concretos nas aulas de matemática:

Manipulação de objetos concretos

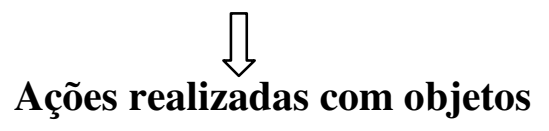

Açoes realizadas com objetos

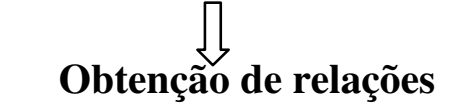

Interiorização dessas relações<smiles>[C+]=C=[C+]</smiles>

Aquisição e formulação do conceito<smiles>[CH]=C</smiles>

Integração do conceito a conceitos anteriores (estruturação)

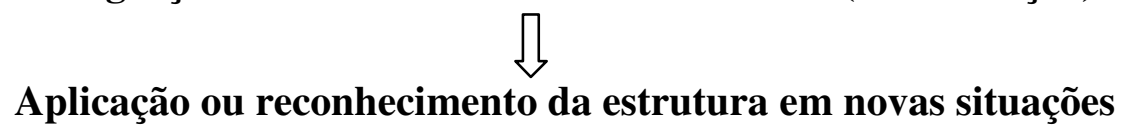

Para complementar essas ações é importante que se faça uso de objetos virtuais, onde o aluno possa aprender a partir de situações experimentais, que torna-se viável, somente nos ambientes informatizados.

Segundo Gravina (1996), é a partir dos experimentos "dinâmicos" que os estudantes vão percebendo as regularidades e os invariantes dos objetos, e a partir da essência do pensamento matemático vai surgindo naturalmente a busca por demonstrações que independem das experiências concretas, no caso as simulações no computador.

Em outras palavras, podemos dizer que o pensamento matemático desenvolve-se a partir de ações suscetíveis a repetições, e isso fica possibilitado a partir do uso de objetos virtuais e softwares de geometria dinâmica, para mais tarde chegar às generalizações.

A matemática é um conhecimento que pode e deve ser explicado, construído e entendido de diversas formas, uma vez que cada pessoa tem a sua maneira de matematizar uma situação-problema, assim a utilização de alguns recursos digitais e não-digitais contribuem para a construção de diversos conceitos matemáticos, dos mais 
básicos aos mais avançados, e ainda estimulam a descoberta e o argumento crítico dos alunos.

\section{Desenvolvendo uma proposta de trabalho a partir de recursos digitais e não-digitais}

As atividades foram implementadas com 60 alunos de $6^{a}$ série, da rede privada de ensino de Porto Alegre, durante aproximadamente oito períodos, no horário regular de aula. A atividade foi dividida em duas etapas: a primeira em sala de aula e a segunda no laboratório de informática.

Inicialmente, foi trabalhado em sala de aula a construção de polígonos regulares. Os estudantes aprenderam a usar o compasso e o transferidor, a medir ângulos e a construir polígonos regulares inscritos no círculo. Juntamente com o professor chegaram a conclusões sobre os ângulos formadores de cada polígono e aos poucos conseguiram desenhar os polígonos regulares no papel.

As tarefas que eles deveriam cumprir eram as seguintes: desenhar quatro polígonos regulares diferentes e após medir seus lados e ângulos internos, assim chegaram a conclusão que os polígonos são regulares quando possuem lados e ângulos iguais. Nos primeiros desenhos as diferenças entre as medidas feitas foram bem perceptíveis, mas conforme foram fazendo os próximos e aperfeiçoando o uso dos instrumentos e do traçado, os desenhos foram ficando melhores e as medidas mais exatas.

A outra parte da atividade foi fazer um desenho livre, usando formas geométricas, que contivesse no mínimo dois polígonos regulares.

A atividade foi muito produtiva, pois despertou o entusiasmo e o interesse dos alunos em aprender, além disso, a criatividade também foi estimulada, como podemos ver nos desenhos abaixo.
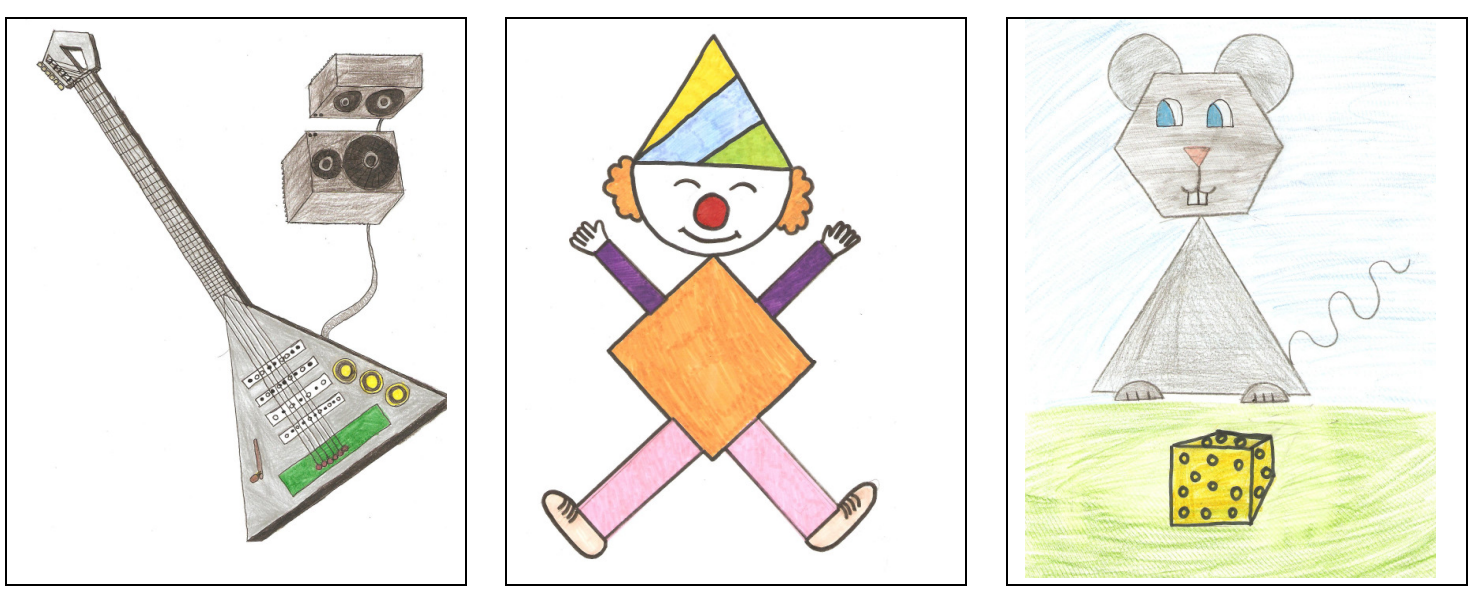

Figura 1 - Desenhos feitos pelos alunos com polígonos regulares

Construir os polígonos manipulando o compasso, a régua e o transferidor trouxe muita autonomia aos alunos, na primeira aula todos precisaram de uma ajuda para posicionar corretamente o transferidor ou para fazer os círculos usando o compasso, mas depois a maioria já estava fazendo sozinho e até auxiliando outros colegas. 
A ideia foi tão bem aceita pelos alunos, que alguns estudantes fizeram mais de um desenho.

Para complementar essa atividade feita em sala de aula, a segunda parte do trabalho foi realizada no laboratório de informática. O recurso utilizado foi o GeoGebra, software de geometria dinâmica, que ainda não era conhecido pelos estudantes. $\mathrm{O}$ software foi apresentado aos alunos rapidamente e logo foi dado um tempo para que eles descobrissem como operar com o programa.

O professor construiu um quadrado no GeoGebra a partir das propriedades, com a finalidade de mostrar aos alunos que assim como no papel, no ambiente interativo também podemos construir um quadrado passo a passo, sem utilizar o recurso "polígono regular" disponível no menu.

Três tarefas foram propostas aos alunos. Na primeira eles deveriam construir o mosaico abaixo (Figura 2), e após responder duas perguntas. A de número um questionava se os triângulos formados entre os hexágonos eram regulares, e a de número dois questionava se era possível encaixar os hexágonos um do lado do outro sem deixar espaços em branco e sem que os polígonos fossem sobrepostos, além disso, as duas respostas deveriam ser justificadas.

As respostas foram variadas e interessantes, alguns descobriram que o software tem o recurso de medir segmentos, e assim afirmaram que os triângulos formados entre os hexágonos eram regulares, pois tinham todos os lados iguais. Outros usaram o recurso de medir os ângulos e também chegaram à mesma conclusão, pois se os três ângulos eram iguais, o polígono era regular, como havíamos visto em aula. Ainda tiveram alunos que desenharam um polígono regular de três lados em cima do triângulo existente, como encaixou perfeitamente também afirmaram que era regular.

$\mathrm{Na}$ segunda pergunta, a maioria respondeu que era possível, pois haviam conseguido encaixar os hexágonos por tentativa e erro. Eles fizeram novos hexágonos e foram colocando-os lado a lado, até formar uma "flor", e assim disseram que era possível.

Eles foram questionados do porquê tinha dado certo, e alguns alunos disseram que sempre que o polígono fosse regular ia dar certo. Aí foram questionados novamente: e se o polígono for de 5 lados, um pentágono regular por exemplo? Será que vai encaixar? Como a resposta havia sido intuitiva foram logo verificar, fizeram o desenho no software e viram que não dava certo, que sobrava uma abertura com um ângulo de $36^{\circ}$. Essa medida precisa foi determinada pelo aluno que descobriu o recurso medir ângulos no menu do software.

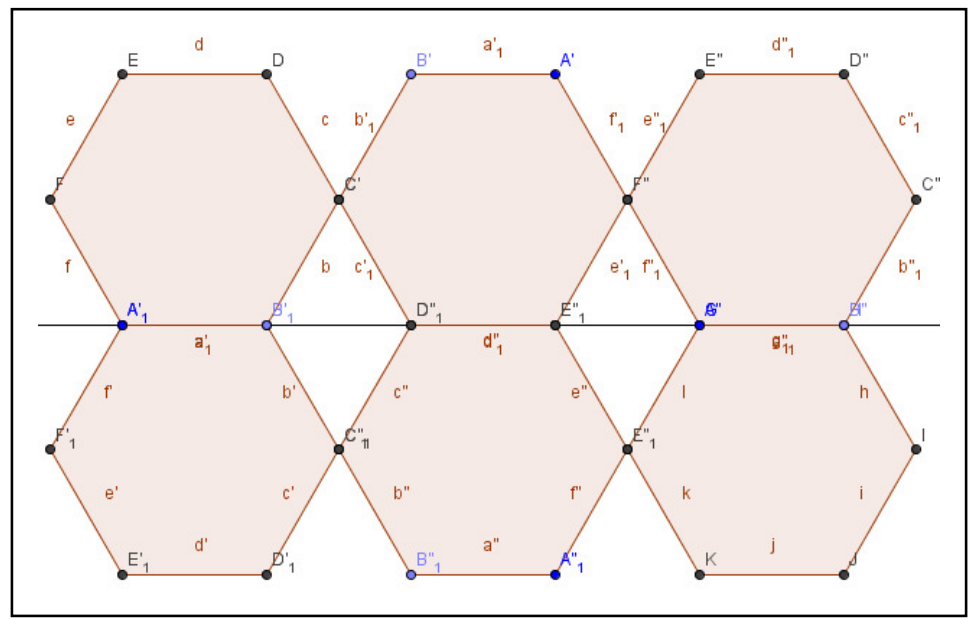


Figura 2 - Imagem da primeira tarefa do GeoGebra

Como a primeira hipótese sugerida por alguns alunos não havia se confirmado, eles começaram a pensar em outras justificativas. Daí, surge o comentário de um outro aluno, que disse o seguinte: "pra ficar uma figura encostada na outra, os cantos tem que fechar um círculo, quando a gente coloca três hexágonos um encostando no outro podemos desenhar um círculo, por isso que dá certo."

Os colegas logo concordaram com ele, e explicamos a eles que, realmente, os polígonos só irão se encaixar quando a soma dos ângulos internos, dos vértices que se encostam, somam $360^{\circ}$. Tentamos usar uma linguagem semelhante a deles, mas que fizesse uso de termos matemáticos.

A segunda tarefa foi construir um mosaico utilizando polígonos regulares. Para facilitar a construção mostramos aos alunos o recurso reflexão por uma reta e reflexão por um ponto, alguns já tinham descoberto enquanto "passeavam" pelo menu e utilizado na construção da figura 2 .

Os mosaicos também ficaram muito criativos, alguns alunos foram "brincando" com os polígonos, até formar um mosaico que gostassem. Já outros pesquisaram na internet para ter ideias e após, montar seus próprios mosaicos.
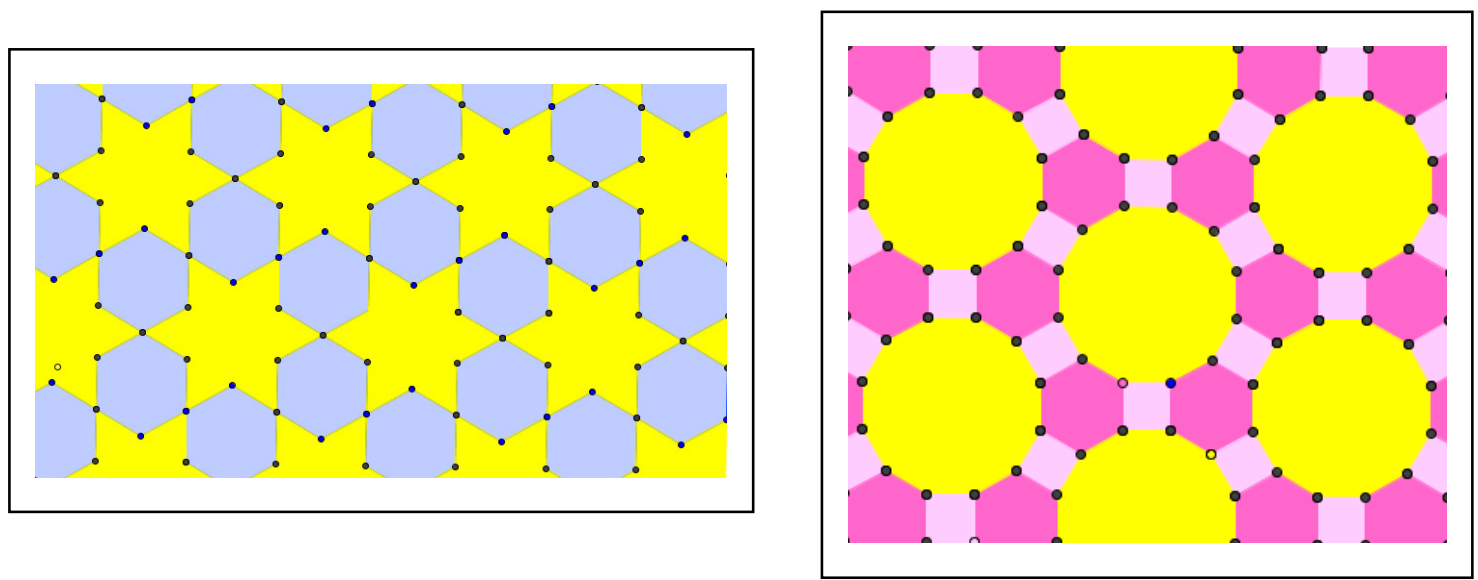

Figura 3 - Mosaicos criados pelos alunos no GeoGebra

Essa parte da tarefa foi a que mais atraiu a turma. Eles ainda não sabiam que era possível colocar cor nos polígonos, e um dos fatos que nos surpreendeu foi o quanto isso é importante para eles, é como se a cor desse "vida" aos desenhos.

$\mathrm{Na}$ última tarefa eles deveriam fazer uma réplica, dos desenhos feitos no papel, no GeoGebra. Foi bem interessante, teve desenhos que realmente ficaram muito semelhantes. Como eles queriam deixar a réplica o mais parecida possível com o desenho original, eles buscaram conhecer todos os recursos que o software oferece, até

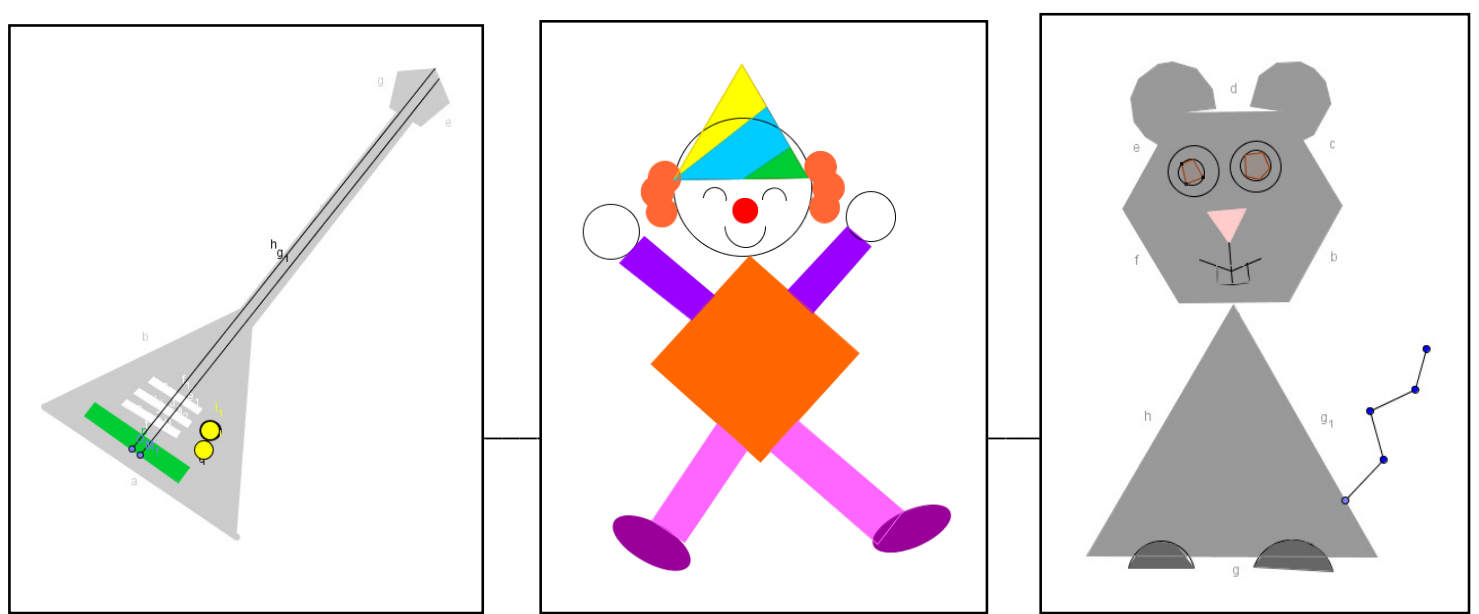


mesmo aqueles não apresentados pelo professor.

Foi muito produtiva essa autonomia que eles foram adquirindo durante o trabalho. Inicialmente, estavam receosos de cometer erros, mas aos poucos foram conhecendo o software e interagindo com ele. Isso refletiu-se em sala de aula, eles estão mais independentes e interessados na resolução das tarefas.

\section{Conclusões e perspectivas}

A utilização do material concreto e dos objetos digitais abrem novas perspectivas para a aquisição do conhecimento. $\mathrm{O}$ aluno deve ser o centro do processo de aprendizagem, e fica evidente que quando fazemos uso dos materiais manipulativos e das tecnologias quem experimenta, interage e vivencia as situações são os alunos.

A partir da atividade desenvolvida, percebemos que vários aspectos tiveram evolução nas turmas. Os alunos aprenderam a se comunicar melhor uns com os outros, a ouvir a opinião dos.colegas, a trabalhar em grupos, a buscar solucõos para os problemas, a justificar as respostas dadas, enfim a trabalhar com autonomia, buscando o seu próprio conhecimento e aprendizado.

Os conceitos matemáticos foram naturalmente entendidos, as experimentações serviram de base para posteriores deduções e demonstrações. Nos diferentes modos de pensar de cada aluno, foram surgindo estratégias de resolução e o conhecimento foi sendo construído.

Sabemos que a utilização desses recursos necessitam de disponibilidade e boa vontade dos professores, as aulas precisam ser bem preparadas e bem encaminhadas. No mais, podemos usar softwares gratuitos, objetos digitais que estão disponíveis gratuitamente na internet e materiais de baixo custo.

Como podemos observar, o uso dos materiais manipulativos possibilita a melhoria do ensino de matemática, não se constitui em um "método mágico" que anule o fracasso escolar, mas sim, em uma proposta que auxilia na elaboração de aulas mais prazerosas, desafiantes e que despertam nos alunos a vontade de aprender.

Assim, a construção do conhecimento, viabilizada pelas atividades manipulativas associadas ao uso da tecnologia, possibilita-nos entender os limites e as possibilidades de cada estudante, para que possamos acompanhar o desenvolvimento do raciocínio construído por eles, focalizando não apenas os resultados obtidos, mas também os caminhos percorridos.

"Podemos dizer para uma criança o que fazer, mas não o que compreender, apenas criar condições para isso, através de atividades manipulativas, para que os estudantes trabalhem com a construção dos conceitos matemáticos." (FIORENTINI, 1995, p.19).

\section{Referências}

FAGUNDES, Léa da Cruz. Materiais manipulativos no ensino de matemática a crianças de 7 a 14 anos - Período das operações concretas. 1977. Acesso online: $<$ http://mdmat.mat.ufrgs.br/PEAD/livros/leituras/01_materias_manipulativos.htm> Acessado em 16 de outubro de 2010. 
FIORENTINI, Dario. Alguns Modos de Ver e Conceber o Ensino da Matemática no Brasil. Revista Zetetiké, Campinas, ano 3, n.4, p. 1 - 38, 1995.

GRAVINA, Maria Alice. Geometria Dinâmica: uma nova abordagem para o aprendizado da geometria. Anais do VII Simpósio Brasileiro de Informática na Educação, p. 1 - 13, Belo Horizonte, 1996.

HOFFMANN, Daniela Stevanin, MARTINS, Elisa Friedrich e BASSO, Marcus Vinícius de Azevedo. Experiências física e lógico-matemática em Espaço e Forma: uma arquitetura pedagógica de uso integrado de recursos manipulativos digitais e não-digitais. XX Simpósio Brasileiro de Informática na Educação, Florianópolis, 2009. 